\title{
Editorial: Critical Turning Points
}

\author{
ELAINE ASTON
}

In July 2010 at the IFTR World Congress held in Munich, I sat listening to Helen Gilbert's keynote address: 'Making Modernity: Indigenous Theatre and Salvage Ethnography'. Aside from the insightful specificities of Gilbert's topic, I was taken immediately by her methodological approach, which involved sifting back through reflections gained from postcolonial cultural studies, sharing the impulse of this work to look at cultures through a transversal lens and to posit their folding together through space and time, ${ }^{1}$ this with a view, for example, to challenging received ideas of indigenous cultures as traditional, the West as modern, and so forth. Broadly speaking, both the paper and the Q \& A that followed it offered a timely and salutary reminder of how knowledge generation is often a sedimentary process: over time certain ideas get deposited and are endlessly mined; others get washed away or eroded. Moreover, this also means that we can find ourselves digging the same old theoretical spaces without looking at the local sites of theatre, performance or culture in ways that might persuade us to excavate elsewhere with different tools and methods. In brief, critical strategies, such as Gilbert's, that variously encourage us to revisit, rethink, rearrange, reconceptualize or recover are important strategies to keep in mind as means to renew and progress our contributions to bodies of theatre and performance knowledge.

In the weeks and months after the congress I looked out (in my TRI mailbox) and listened out (at conferences and events), and otherwise encouraged contributions that might similarly help us to think back through the layers of accumulated knowledge about defining aspects of or seminal concerns in the field of theatre and performance studies. Hence pivotal to each of the contributions brought together in this issue of TRI is a critical turning point: a point of reflection that looks back with renewed interest and insight on its subject matter or topic.

The issue opens with a contribution from former TRI editor Freddie Rokem on philosophy and theatre. In his final issue as editor (TRI, October 2009) Rokem assembled articles focused on encounters between performance/theatre and philosophy, arguing that we have now 'entered a phase of critical re-examination of the philosophical foundations of theatre and performance'. ${ }^{2}$ Here, Rokem offers his own 'critical reexamination' of the relations between philosophy and theatre and their discursive practices by analysing how the board games of chess and go apply to the philosophical 
thinking and artistic practices of Walter Benjamin and Bertolt Brecht. In the 'dramaturgies of exile' patterned in the board games, but also lived by Benjamin and Brecht, who both left Germany after Hitler's rise to power, Rokem finds a 'hermeneutic key' that unlocks not only the narrative strategies in works by the two respective 'players', but also a rich and insightful understanding of how the larger 'game' of theatre and philosophy plays out as a 'complex interaction between concrete situations involving human subjects and abstract ideas, between doing and thinking'.

Rokem's article is accompanied and complemented by Laura Cull's reflections on performance and philosophy. Narrowing her focus to the vexed question of 'application', Cull cautions against the hierarchical application of philosophy to performance that can occur from either side of the philosophical and artistic divide, pressing instead for more egalitarian relations in which performance is conceived as 'a way of thinking' in its own right. With this in mind, she advocates a return to philosophies, such as those of Gilles Deleuze and Henri Bergson, as a 'sound conceptual basis from which to argue that the ephemeral, material work of performance does not need an interpreting, anthropocentric subject standing outside it in order for it to have "meaning"' and can, therefore, 'provide us with the resources to rethink performance itself as a kind of philosophy, and indeed to reconceive what counts as philosophy'.

The philosophies of Bergson and Deleuze resurface in Mark Fleishman's article concerned with performance as research $(\mathrm{PaR})$. As Cull reflects in her concluding thoughts, $\mathrm{PaR}$ 'has already gone some way to explore the nature of performance's kind of thinking'. Yet what 'kind of thinking', what kind of 'difference' PaR makes to knowledge generation is taken up by Fleishman as a matter of debate as he looks back over the emergence of $\mathrm{PaR}$ and forward to his own experientially formed thinking. It feels timely to have a contribution on PaR in this issue of TRI-this not only because of its recent impact on the field of theatre and performance studies, but also because of what Fleishman observes as the burgeoning interest in PaR 'across geographical boundaries and particularly away from the Euro-American academic context'. Hence it is not surprising, perhaps, to note that my initial encounter with Fleishman's 'take' on PaR, as detailed here, occurred in the context of an international workshop for postgraduate students hosted by the University of Hyderabad, India (January 2011). ${ }^{3}$ At this event, a real hunger and desire to wrestle with what $\mathrm{PaR}$ is, how to adopt and adapt it for local needs and contexts, was palpable among those participants engaging in professional practice as part of their studies. It will be interesting to see how PaR takes root and develops in India and what this brings to the thinking-through-practice debates in the future.

Moving on from thinking through the relatively new subject of $\mathrm{PaR}$, Nicholas Johnson's article engages with the work of Samuel Beckett, a writer/practitioner whose creativity has generated a veritable industry of critical studies. Indeed Beckett and Brecht, who is 'key' to unlocking Rokem's re-examination of theatre and philosophy relations, are arguably the two most prominent playwrights of the last century, and it interesting to note each of these major, twentieth-century figures resurfacing in this issue as pivotal to respective sites of renewed thinking. Observing the recent empirical and archival wave of Beckett studies, Johnson argues that while this kind of 'excavation' can be insightful in terms of dealing with the past, it 
is not wholly equipped to deal with the present or future Beckett. Thus it cannot answer (or ask) certain challenging questions: why is Beckett a figure to whom we keep returning? What are the durable ideas within his aesthetic contribution, and what can they tell us about the century of their birth?

Returning to Beckett, Johnson looks instead to an idea of 'a performative Beckett who is not a deceased artist, but a living idea'; explores Beckett's usage of 'language, multiplicity, void' as a means to reflect on the 'modernist subject', and offers a provocation to 'postmodern thought' by positing 'a kind of really-existing modernism'. Moreover, from the point of view of the Beckettian subject as Johnson presents and argues it, a postmodern tendency to conceal the 'void at the heart of presence, being and thought' leaves 'the subject ... in crisis, not because of new insights or new technologies, but because of the old ones'.

The specifics of this last point remind one in more general ways that looking back to 'old' insights with a view to what might have been missed or overlooked can be critically productive, rather than necessarily looking out for the next 'new' theory, philosophy or criticism. Resonant throughout the issue, the impulse to revisit and reassess is taken up in Paul Murphy's discussion of 'Class and Performance in the Age of Global Capitalism'. Here, Murphy looks back over theatre and performance studies to offer an account of how class-based analysis has to a significant degree fallen into the margins of theatre and performance scholarship. Focusing on what he argues as a critical blind spot and drawing on the work of Bourdieu, among others, Murphy moves to rethink 'class as practice and performance rather than as an identity predicated solely on economic stratification', an approach he exemplifies through an analysis of the 2003 Dublin production of Declan Hughes's Shiver.

Thinking back through class politics, Murphy touches on the histories of feminist activism and identity politics, revisited in the final contributions to this issue: a multivoiced, critical forum of feminist reflections on identity politics, theatre and performance. Introduced, compiled and edited by Elin Diamond, the forum offers a range of international views and perspectives from Nobuko Anan (Japan), Denise Varney (Australia), Katrin Sieg (Germany), Bishnupriya Dutt (India) and Tiina Rosenberg (Sweden). Threaded through different geographies of feminism, theatre and performance, the fabric of identity politics emerges in the forum as an uneven weave of progressive histories and reductive setbacks; of identity claims and the essentialist risks of claiming; of challenges, contestations, renewals and misappropriations. Nothing is, or can possibly be, settled, but in turn this unsettles the idea that the 'old' identity debates are over or not worth reopening and re-examining.

After the first decade of the twenty-first century all of these articles in their quite different ways seek to reconfront issues, legacies and failures of the previous century; collectively, they question considerations of what new beginnings might be possible, and where these might appear or take root. Overall, I hope this issue of TRI assists with returning to, rethinking or reopening the subjects presented here, and prompts further reflections on these or other topics and matters that might be thought about as pivotal to the past, present and future field of theatre and performance studies. 


\section{NOTES}

1 The idea of folding was key to Gilbert's thinking as she sought to make connections across time, space and cultures in her 're-visiting [of] salvage ethnography as one specific co-constitutive field of practice folded into the terrain of imperial modernity'. Helen Gilbert, 'Making Modernity: Indigenous Theatre and Salvage Ethnography', unpublished paper.

2 Freddie Rokem, 'My Last Editorial', Theatre Research International, 34, 3 (October 2009), pp. 227-9, here p. 228.

3 Theorising Practice and Practicing Theory in Theatre was organised by B. Ananthakrishnan at the University of Hyderabad (30 January-3 February 2011) as an international workshop for young researchers and practitioners. 